\title{
A RESIDÊNCIA PEDAGÓGICA E O USO DE FANFIC PARA O LETRAMENTO DIGITAL NA EDUCAÇÃO BÁSICA
}

\author{
PEDAGOGICAL RESIDENCE AND THE USE OF FANFIC FOR DIGITAL LETTERING IN \\ BASIC EDUCATION
}

Jakson Queiroz Ramos ${ }^{1}$

Maristela Midlej Silva de Araújo²

RESUMO: O artigo tem por finalidade relatar a experiência desenvolvida na Universidade Federal do Sul da Bahia (UFSB), partindo da construção do Programa de Residência Pedagógica (PRP) no Curso de Ciências Humanas e Sociais e Suas Tecnologias. A base teórica dessa apresentação foi inspirada na concepção de "Multiletramentos e as Novas Tecnologias de Informação e Comunicação nas práticas de leitura e escrita da Educação Básica", produzindo uma metodologia inovadora para uma intervenção didática junto aos estudantes do $\mathrm{I}^{\circ}$ ao $3^{\circ}$ ano médio do Complexo Integrado de Educação de Itabuna (CIEI), e assim descrever as práticas de letramento dos diversos gêneros discursivos, linguagens e códigos destes seguimentos educacionais. Certificando o conceito de rever práticas docentes referente a produção de texto convencional presente na escola. Este artigo ancora-se teoricamente em estudos sobre letramentos em Kleiman (2002, 2006 e 2007), sobre Multiletramentos em (Rojo 2009, 2013).

Palavra-chave: Mídias-digitais. Multiletramentos. Tecnologias. Comunicação. Fanfic.

ABSTRACT: The article aims to report the experience developed at the Federal University of Southern Bahia (UFSB), starting from the construction of the Pedagogical Residency Program (PRP) in the Course on Human and Social Sciences and Its Technologies. The theoretical basis of this presentation was inspired by the conception of "Multiliteracies and the New Technologies of Information and Communication in the reading and writing practices of Basic Education", producing

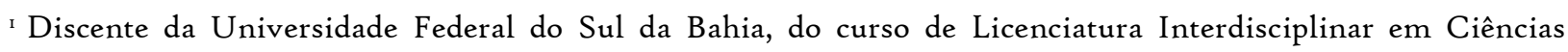
Humanas e Sociais e Suas Tecnologias. Licenciado em Pedagogia pela UNIME-Itabuna (Bolsista do Pro-Uni). Professor na rede particular de ensino da Educação Básica. Bolsista Residência Pedagógica/CAPES. E-mail: jakson.ramos@cja.ufsb.edu.br.

${ }^{2}$ Doutora em Educação pela Universidade Federal da Bahia (2014). Mestre em Educação pela Universidade Federal da Bahia (2007). Especialista em Informática na Educação pela Universidade Estadual de Feira de Santana (1998). Especialista em Gestão e Planejamento de sistemas em EAD pela Universidade do Estado da Bahia (2004). Possui graduação em Letras pela Universidade Estadual de Santa Cruz (199I). É docente da Universidade Federal do Sul da Bahia. Tem experiência na formação inicial e continuada de professores na área de Educação, com ênfase em Tecnologia na Educação, principalmente nos seguintes temas: formação de professores, educação online e cibercultura. Atuou como professora do Curso de Pedagogia para formação de professores em serviço PROAÇÃO UESC. Atuou como professora do Curso de Pedagogia da União Metropolitana de Educação e Cultura UNIME. Coordenou e foi docente do Módulo de Práticas Pedagógicas e TIC na especialização Tecnologias e Novas Educações da UFBA. Atuou na docência do Projeto Irecê/Tapiramutá - Curso de Formação de professores em serviço da Universidade Federal da Bahia. Foi docente do Núcleo de Tecnologia Educacional (estadual) e do Núcleo de Tecnologia Municipal - Itabuna-Ba.
} 
an innovative methodology for a didactic intervention with students from the ist to the $3 \mathrm{rd}$ middle year of the Integrated Education Complex of Itabuna (CIEI), and thus describe the literacy practices of the diverse discursive genres, languages and codes of these educational segments. Certifying the concept of reviewing teaching practices regarding the production of conventional text present in the school. This article is theoretically anchored in studies on literacies in Kleiman (2002, 2006 and 2007), on Multiliteracies in (Rojo 2009, 2013).

Keyword: Digital media. Multi-tools. Technologies. Communication. Fanfic.

\section{INTRODUÇÃO}

A Nova Base Comum Curricular, pede novo um perfil de professor, de maneira que seja uma atuação voltada para os estágios de desenvolvimento do educando, que se ajuste a partir de competências e habilidades. Dessa forma, esse artigo tem o objetivo de apresentar os resultados obtidos durante a vivência no Projeto de Residência Pedagógico (RP) e do subprojeto Multiletramento no Complexo Integrado de Educação de Itabuna (CIEI).

A ação pedagógica da RP, teve como eixo principal contribuir para sanar ou diminuir a dificuldade dos estudantes em leitura, produção e interpretação de texto que se mostrou como barreira a ser vencida pelos educandos. "Ler não é decifrar, escrever não é copiar", (FERREIRO, 1985, p.16).

Entendendo que o século XXI, a complexidade dos processos educativos tornou-se mais evidente, demandando, assim, reflexões, pesquisas e aplicações que explorem as potencialidades das redes sociais colaborativas, ou as potencialidades das redes sociais facebook, blogs e aplicativos de mensagens eletrônicas. A inserção da banda larga nos espaços educacionais deveria ter se tornado uma constante sendo, pois, necessária ao fomento da prática docente, como também contribui para o desenvolvimento tecnológico do educando.

Quando o uso da internet se disseminou, existia um pensamento que o seu impacto seria mito forte nos primeiros anos, que teríamos metodologias muito diferentes, mais participativas e adaptadas a cada estudante, não vislumbramos isso nos colégios que, deveriam ter um suporte de banda larga que suportasse tal demanda, nem nos domicílios dos mesmos que, por muitos apresentarem situação de vulnerabilidade, a internet não possibilita uma conexão limpa para desenvolvimento dessas práticas, que se mostrou um dos principais problemas no desenvolvimento do projeto.

\section{Apresentação e Problema}

Após o período de ambientação do Programa de Residência Pedagógica, adentramos a mais uma importante etapa que é a intervenção. Nivelado ao principal problema detectado pelo corpo docente do Complexo Integrado de Educação de Itabuna (CIEI), a dificuldade dos estudantes em leitura, produção 
e interpretação de texto tem se mostrado como barreira a ser vencida pelos educandos. "Ler não é decifrar, escrever não é copiar", Emília Ferreiro.

Partindo de uma concepção interdisciplinar, e visando atender a demanda de melhoria de escrita e produção apontada pela escola como um problema ser combatido, propomos uma intervenção pautada em escritas de fanfics (Faz Fanfic), que comunga com o eixo de uma das propostas de intervenção apresentada ao colégio pela equipe de Multiletramentos, que tem como professora orientadora Maristela Midlej Silva de Araújo Veloso e a supervisora no (CIEI) a professora Aline Ferreira, juntamente com o residente Jakson Queiroz Ramos.

Para inserir o projeto, e alcançar os objetivos listados, utilizamos como espaço físico a sala de multimeios, está foi equipada com os cromebooks, que junto ao acesso de banda larga do colégio, seria nosso maior aliado.

Com a internet e as tecnologias móveis, desenvolvemos formas abrangentes de comunicação, escrita, fala e narrativa audiovisual. Fundamentalmente o que fazemos hoje na 'internet' é escrever para fazer registros (ideias, notícias, sentimentos) para publicar (divulgar páginas, serviços, etc.) e para nos comunicar, de se relacionar, presencial e virtualmente. Toda essa construção, reforça de maneira positiva a inserção de utilizar as mídias sociais, em favor do estímulo à produção de texto, partido das construções de fanfics (escrita e reescrita), que é a produção de (ficção de fã), um gênero emergente que circula na internet. Os fanfics produzidos são publicados em blog específico. Essa iniciativa comunga com a principal proposta do Colégio em encontrar meios, maneiras de melhorar os índices de escrita, produção e interpretação te textos da sua comunidade escolar secundarista.

Essas ideias se firmam na coexistência entre as tecnologias impressas e digitais de leitura e escrita na comunidade escolar atual, combinando os mais diversos tipos de imagens, com áudios, cores, links, nos ambientes digitas para transformá-las em mídias impressas. Possibilitando assim novas maneiras de ensino e aprendizagem que considerem os "letramentos múltiplos, ou Multiletramentos, abrangendo leitura crítica, análise e produção de textos que possibilitem várias linguagens multicultural”. (ROJO, 2013, p. 8).

\section{Produzindo Fanfics}

O projeto FAZ FANFIC, foi trabalhado uma vez por semana nas turmas do $\mathrm{I}^{\circ}$ ao $3^{\circ}$ ano médio do Complexo Integrado de Itabuna nas aulas de produção de texto durante um trimestre. Os estudantes são apresentados aos conceitos de estrutura de textos narrativos e de construções de etapas para depois 
ser inserido de fato o gênero FANFIC. Nessa etapa serão utilizados slides para ambientação e pequenas atividades práticas para sedimentação do gênero textual oferecido. Cada etapa do projeto é mostrada aos estudantes que a construção do Fanfic deve partir do interesse de cada um, podendo assim, ser construídas histórias independentes ou não.

Mas o que é uma fanfic mesmo? É um termo derivado de fanfiction e:

Fanfiction é a escrita na qual os fãs usam narrativas midiáticas ou ícones culturais como inspiração para criar seus próprios textos. Em tais textos, os fãs autores imaginativamente estendem o enredo ou a cronologia original (...) criam novos personagens (...) e/ou desenvolvem novos relacionamentos entre personagens já presentes na fonte original. (CAVALCANTI, 2010).

Neste caso, o gênero trazido para a sala de aula foi a fanfiction, também chamada de fanfic: que parte do interesse do educando em animes, jogos de videogame, novelas, os desenhos animados, os filmes e as séries de televisão e de contos e textos literários, etc. A fanfic é uma produção de um texto narrativo-ficcional feito por fãs das mais diversas mídias visuais.

Tendo como ponto forte a interdisciplinaridade, na construção e reconstrução das histórias, possibilitou um desenvolvimento nas disciplinas de História, Geografia e Sociologia, em cada etapa, eram refletidos sobre relevo, planaltos e planícies. A estrutura social, também presente nas narrativas, em sua maioria, trazendo para os fanfics, o cotidiano, o dia a dia dos educandos. "A prática social é compatível com o trabalho analítico necessário para a sistematização, domínio e controle dos saberes, inclusive o conhecimento dos gêneros envolvidos nessa prática (...)”. (ROJO. 2013, p. 35).

Usando como plano de fundo a construção dos fanfics, os estudantes participaram de oficinas para compreenderem o que é um blog, as partes de postagens e edição dos mesmos, haja vista que cada história será postada na referida plataforma de compartilhamento digital. Os estudantes também aprenderam como fazer edição e formatação de textos, usando os cromebooks disponíveis no colégio como instrumento didático pedagógico, para alimentar o blog C.I.E.I Faz FanFic.

\section{Resultados Obtidos}

Ao finalizar o trimestre, as turmas que mergulharam nos conhecimentos do letramento digital, desenvolveram habilidade na produção e edição de vídeo, que passaram a incorpora cada vez mais o cotidiano. Os estudantes, baixaram músicas, recorreram às mídias sociais e construíram histórias, avançaram nas construções dos textos, identificavam as partes nas construções de textos, fizeram leituras on-line e perceberam que o celular serve para conversar, enviar mensagens, acessar a internet, 
construir textos e postá-los. As tecnologias caminham na direção da integração, da instantaneidade, da comunicação audiovisual e interativa.

Os secundaristas do CIEI, entenderam que, com a web 2.0, temos muitas tecnologias simples baratas e colaborativas, como o "blog", Wiki, ou o Google Docs., que os estudantes

Passaram a conhecer como uma das ferramentas que possibilitavam a escrita e reescrita das histórias dos Fanfics, ou o Twitter, Facebook, ferramentas que permitem que os educandos sejam produtores, divulgadores de suas pesquisas e projetos, de formas muito mais ricas e estimulantes.

Figura I - Oficina de construção de FanFic 2019

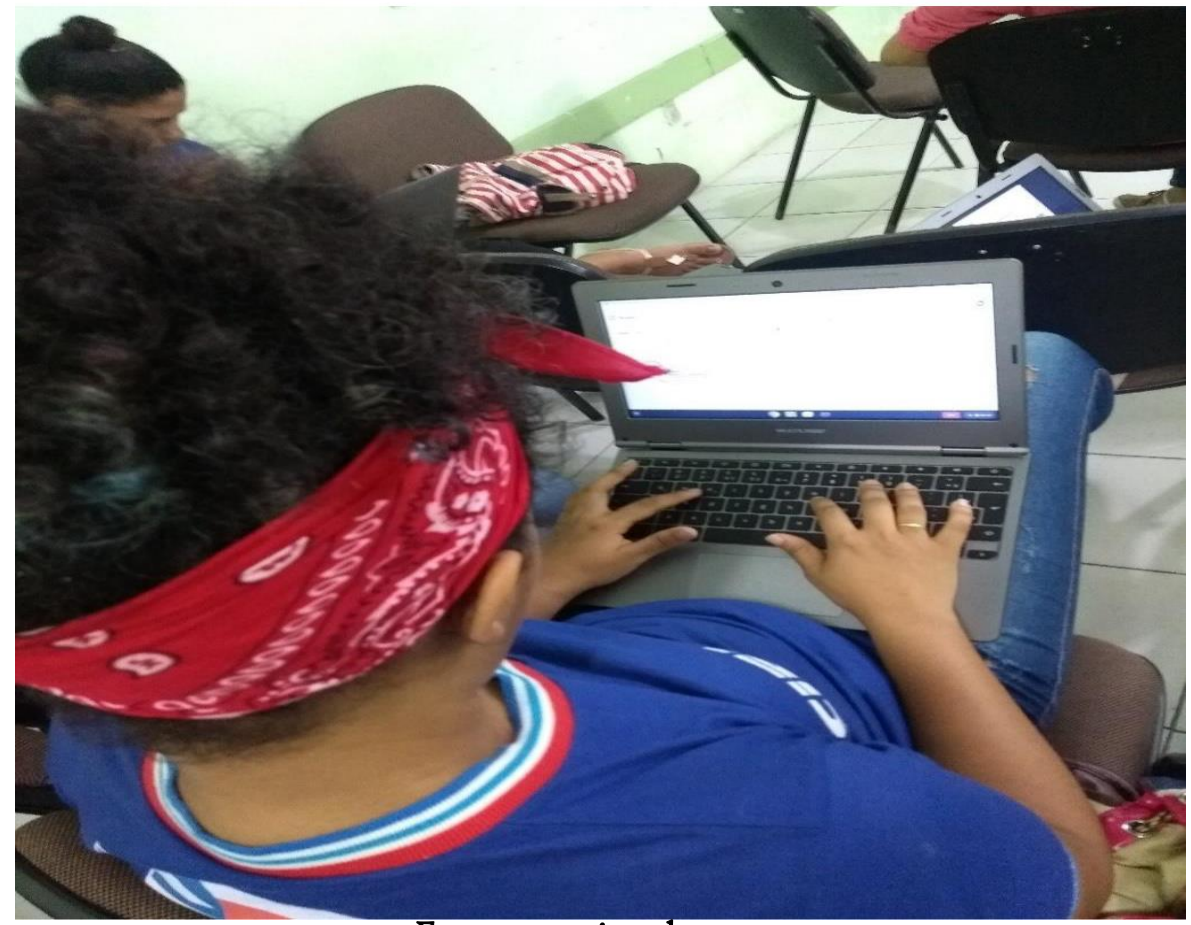

Fonte: arquivo do autor

Os blogs são muito utilizados pelos estudantes, porém, a maneira de usar foi modificada, antes, os mesmos passeavam, bebiam nessas fontes digitais. Com a utilização dos fanfics, os educandos se colocaram na posição de construtor de conteúdo, assuntos, temas dos mais variados gêneros textuais, trabalhados de maneira maçante e vertical nas salas de aula.

O blog, como espaço de divulgação pessoal, de demonstração de identidade, onde se misturam narcisismo e exibicionismo, em diversos graus. Atualmente, há um uso crescente de blogs por professores, que passaram também a entender tão quão poderosa ferramenta de 
desenvolvimento de aprendizagem, eles se mostram. Os blogs como plataformas educacionais, permitem a atualização constante da informação, favorecem a construção de projetos, individuais e em grupo, e a divulgação de seus trabalhos.

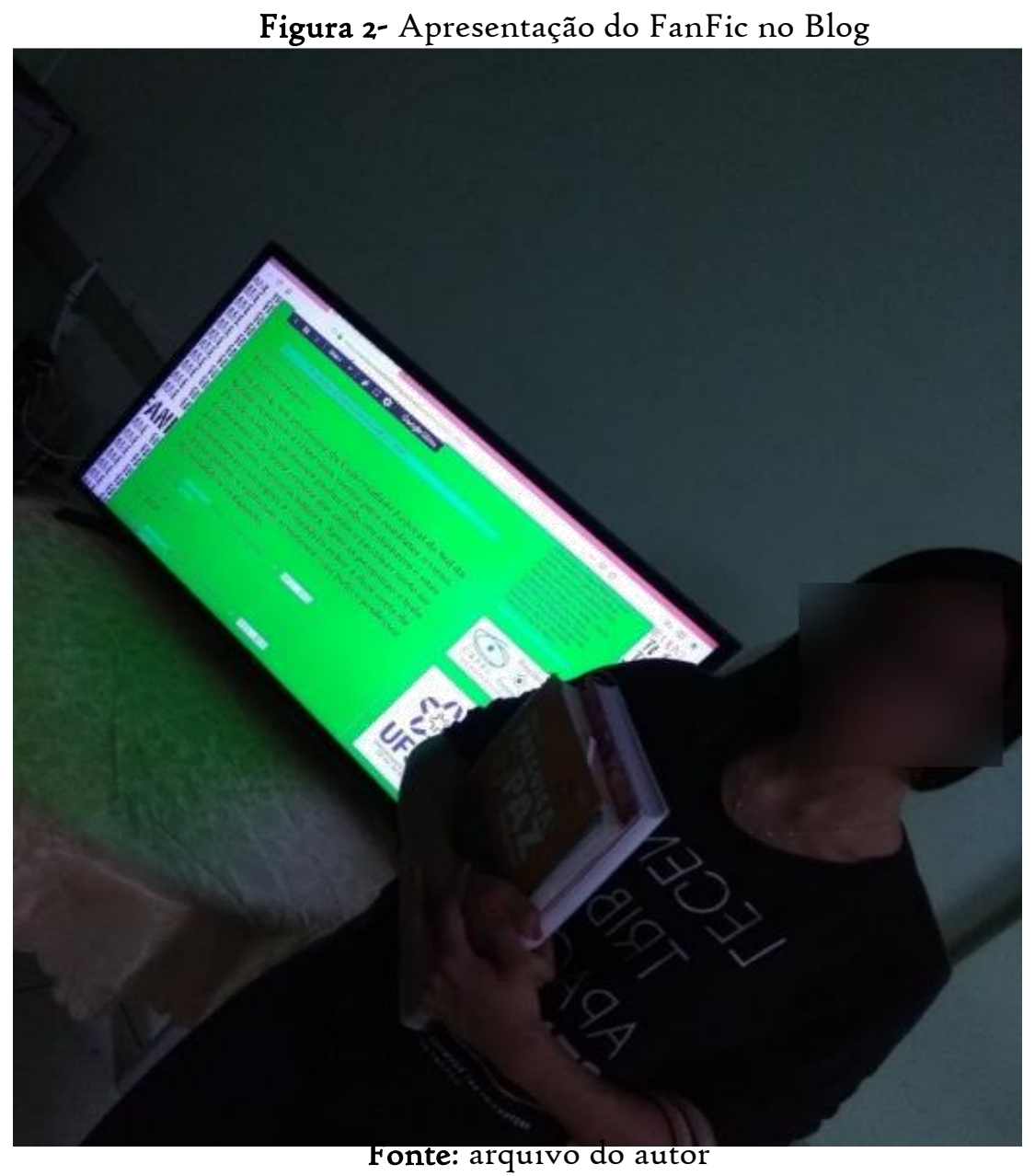

\section{Considerações Finais}

Apesar de ainda estarmos engatinhando no que diz respeito a inserção do uso de banda larga nas escolas e colégios, como também a logística necessária para implementação de espaços com periféricos que permitam acesso à rede, o projeto $\mathrm{Faz}$ Fanfic, se mostrou eficaz em atingir os objetivos, pois entendemos que a internet disponibiliza a tecnologia da informação a um grupo imenso de pessoas, que podem conectar à rede, passando a ser usuários do universo de informações e formador de conteúdos organizados no mundo inteiro. Trazer para o colégio a possibilidade de estudantes secundaristas melhorarem a leitura e produção de texto utilizando 
dessas ferramentas é no mínimo, necessário.

A internet permite a formação de grupos de discussão por meio das mais diversas mídias sociais. Esse processo se amplia com a possibilidade de dialogar com outros usuários, tornandose um instrumento significativo para o processo educativo em seu conjunto. Ela possibilita o uso de textos, sons, imagens e vídeo que subsidiam a produção do conhecimento. Além disso, as plataformas dos blogs, propicia a criação de ambientes ricos para ação: escrita, correção, reescrita e publicação de maneira prazerosa, rica, trazendo processos colaborativos e cooperativos.

\section{Referência}

CAVALCANTI, S. Lana. Geografia, Escola e Construção de Conhecimentos. Editora Papirus. São Paulo. 20I0.

A Geografia Escolar e a Cidade. Editora Papirus. São Paulo. 2010.

FERREIRO, Emília. Reflexões sobre alfabetização. São Paulo: Cortez, 1985, p.i6 ROJO, Roxane.

Letramentos múltiplos, escola, e inclusão social. São Paulo: Parábola Editorial, 2009. 128p.

ROJO, Roxane. Gêneros discursivos do Círculo de Bakhtin e multiletramentos. In: (Org.).Escol@

Conectada: Os multiletramentos e as TICS. São Paulo: Parábola, 2013. p.13-36 